\title{
Estimated and Measured GFR Associate Differently with Retinal Vasculopathy in the General Population
}

Bjørn Odvar Eriksen MD PhD ${ }^{1,4,7}$, Maja-Lisa Løchen MD PhD², Kjell Arne Arntzen $\mathrm{MD}^{3,5}$, Geir Bertelsen $\mathrm{MD}^{3,6}$, Britt-Ann Winther Eilertsen $\mathrm{RN}^{7}$, Therese von Hanno $\mathrm{MD}^{3,9}$, Marit Herder $\mathrm{MD}^{2,8}$, Trond Geir Jenssen MD $\mathrm{PhD}^{1,10}$, Ulla Dorte Mathisen MD $\mathrm{PhD}^{4}$, Toralf Melsom $\mathrm{MD} \mathrm{PhD}^{4}$, Inger Njølstad $\mathrm{MD} \mathrm{PhD}^{2}$, Marit D. Solbu MD $\mathrm{PhD}^{4}$, Ellisiv B. Mathiesen $\mathrm{MD} \mathrm{PhD}^{3,5}$

${ }^{1}$ Metabolic and Renal Research Group, ${ }^{2}$ Dept. of Community Medicine, ${ }^{3}$ Dept. of Clinical Medicine, Faculty of Health Sciences, UiT The Arctic University of Norway; ${ }^{4}$ Section of Nephrology, ${ }^{5}$ Dept. of Neurology and Neurophysiology, ${ }^{6}$ Dept. of Ophthalmology, ${ }^{7}$ Dept. of Clinical Research, ${ }^{8}$ Dept. of Radiology, University Hospital of North Norway, Tromsø; ${ }^{9}$ Dept. of Ophthalmology, Nordland Hospital, Bodø; ${ }^{10}$ Oslo University Hospital, Oslo, Norway

Running head: GFR and Retinal Vasculopathy in the General Population Word count: 3156

Number of references: 41

Address for correspondence: Bjørn Odvar Eriksen, Section of Nephrology, University Hospital of North Norway, 9038 Tromsø, Norway

Fax:+4777628060; Telephone: +4777626856; E-mail: bjorn.odvar.eriksen@unn.no

Keywords: CKD, chronic renal failure, vascular disease, bias, central retinal artery equivalent, central retinal vein equivalent, general population, iohexol, retinopathy 


\section{Abstract}

Background/Aims: Estimated GFR (eGFR) is used extensively in epidemiological research. Validations of eGFR have demonstrated acceptable performance, but the dependence of creatinine and cystatin C on non-GFR factors could confound associations with disease. Few studies have investigated this issue in direct comparison with measured GFR (mGFR). We compared the associations between eGFR and mGFR and retinal vasculopathy, a marker of systemic microvasculopathy.

Methods: Iohexol clearance and retinal photography were examined in the Renal Iohexol Clearance Survey in Tromsø 6 (RENIS-T6), which consists of a representative sample of middle-aged persons from the general population. A total of 1553 persons without selfreported kidney disease, cardiovascular disease or diabetes were investigated. Three eGFR equations based on creatinine and/or cystatin $C$ from the CKD-EPI-Collaboration were studied. Differences between eGFR and mGFR were analyzed with seemingly unrelated regression methods.

Results: mGFR in the lowest quartile was associated with an increased multivariableadjusted odds ratio of retinopathy (OR 1.86, 95\% confidence interval 1.16-2.97), but not with retinal artery or vein diameters. eGFR $_{\text {cys }}$ was consistently biased relative to mGFR in its associations with retinal vessel diameters across different models. eGFR $\mathrm{crea}_{\text {and }}$ eGFR $\mathrm{cyscrea}_{\text {a }}$ were also biased in several of these models $(\mathrm{P}<0.05)$. For retinopathy, the differences between the three eGFRs and mGFR were not statistically significant.

Conclusions: Low mGFR is associated with retinopathy in the general population. eGFR based on creatinine and/or cystatin C are not valid substitutes for mGFR in studies of the relationship between the retina and kidney function in healthy persons. 


\section{Introduction}

The GFR is difficult and costly to measure accurately in epidemiological research. For this reason, equations have been developed to estimate the GFR using endogenous substances,

primarily serum creatinine and cystatin $C$. These equations have been shown to have acceptable bias and precision relative to the measured GFR (mGFR). Estimated GFR (eGFR) is now being used as proxy for mGFR in most epidemiological studies of kidney function.

Creatinine and cystatin C have been shown to be influenced by non-GFR factors [1-4]. Accordingly, the difference between mGFR and eGFR is not random measurement error but partly caused by factors that could also be correlated with disease. Estimates of disease risk based on eGFR could be biased even though the eGFR estimates themselves are unbiased. The difference observed between risk estimates associated with eGFR based on creatinine vs. cystatin $\mathrm{C}$ indicates that this is the case. It has been hypothesized that combining endogenous filtration markers with different non-GFR determinants in the same estimating equation could alleviate this problem.

The Chronic Kidney Disease Epidemiology Collaboration (CKD-EPI) equation based on both creatinine and cystatin $\mathrm{C}$ is to date the best-validated estimating equation based on this principle [5]. However, although it has been found to have less bias and better precision than equations based on either substance alone, it is not known whether it is more similar to mGFR in its associations with clinical manifestations. Because the non-GFR determinants of creatinine and cystatin C differ, it is possible that they cancel out and that this equation is less susceptible to such influences. 
We examined this issue in relation to the retinal microvasculature. Retinopathy and narrower retinal arteries and wider veins predict manifest cardiovascular disease (CVD) [6,7]. The vascular beds of the choroid and the glomeruli share several structural similarities, and important physiological mechanisms as the renin-angiotensin-aldosterone system are found in both the eye and the kidneys [8]. Accordingly, pathogens that affect the retinal microvasculature would also be expected to influence the glomeruli, as can be seen in e.g. diabetes and hypertension [9,10]. However, studies of the eGFR and retinal microvascular in the healthy general population have reached different results, which may partly be due to nonGFR influences on creatinine and cystatin C. The Renal Iohexol-clearance Survey in Tromsø 6 (RENIS-T6) has the largest population-based cohort with mGFR measured as iohexol clearance, which is accepted as an accurate method [11 ]. The cohort, which consists of a representative sample of the middle-aged general population without manifest CVD, diabetes or chronic kidney disease, has also been investigated with retinal photography. The aim of the present investigation was to compare the associations between retinal vasculopathy, mGFR and the CKD-EPI eGFR equations based on creatinine and/or cystatin C [5]. 


\section{Methods}

\section{Study Population}

The RENIS-T6 was an ancillary part of the sixth survey of the Tromsø Study, as previously described [12 ]. Those invited to the sixth survey (October 2007 to December 2008) included a 40\% random sample of individuals aged 50 to 59 years drawn from the population registry and all individuals aged 60 to 62 years (5464 total subjects). Of these, 3564 subjects aged 5062 years completed the survey. We excluded 739 subjects with self-reported myocardial infarction, angina pectoris, stroke, diabetes mellitus or renal disease. The remaining 2825 eligible subjects were invited to the RENIS-T6. Of the 2107 who responded, we excluded 12 due to an allergy to contrast media, iodine or latex; 65 due to other reasons; and 48 who did not present for their appointments. A total of 1982 subjects remained for inclusion, and 1632 were investigated according to a predefined target. Five participants were excluded due to technical failures in their GFR measurements, leaving 1627 included participants in the RENIS-T6 cohort (Figure 1). The cohort has been shown to be representative of all 2825 eligible subjects [13].

For the present analyses, persons with a urinary albumin-creatinine ratio (ACR) >1.92 $\mathrm{mg} / \mathrm{mmol}$ for men or $2.83 \mathrm{mg} / \mathrm{mmol}$ for women [14] or diabetes (fasting serum glucose $\geq 7.0$ $\mathrm{mmol} / \mathrm{L}$ or hemoglobin $\mathrm{A}_{1 \mathrm{C}} \geq 6.5 \%$ ) were excluded [15].

A health questionnaire was administered. A family history of early myocardial infarction was defined as a first-degree relative with myocardial infarction before the age of 60 years. 
Physical exercise was defined as leisure time activity leading to perspiration or breathlessness.

This study was approved by the Norwegian Data Inspectorate and the Regional Committee for Medical and Health Research Ethics of North Norway. Written informed consent was obtained from all individual participants included in the study. All procedures performed were in accordance with the ethical standards of the institutional and/or national research committee and with the 1964 Helsinki declaration and its later amendments or comparable ethical standards.

\section{Retinal Vessel Diameters and Retinopathy}

Retinal photography was performed with a Visucam PRONM (Carl Zeiss Meditec, Jena, Germany) retinal camera. Computer-assisted measurements of the diameters of all vessels coursing through the area of one-half to one disc diameter from the optic disc margin were performed. Of each type, the six largest were summarized as the central retinal artery equivalent and the central retinal vein equivalent [16].

Retinopathy grading was based on "The International Clinical Diabetic Retinopathy and Diabetic Macular Edema Disease Severity Scales”[17]. Microaneurysms, hemorrhages and cotton-wool spots were counted. The grade for the worse eye was used. For the counts of microaneurysms, hemorrhages and soft exudates, the sums of the counts for both eyes were used. The details have been published previously [18]. 


\section{Iohexol Clearance}

The GFR was measured as the single-sample plasma clearance of iohexol, which has been validated against gold standard methods [11,19-21]. The details have been published previously [12].

\section{Other Measurements}

The methods for measurements of conventional and ambulatory blood pressure (BP) have been described previously [22]. Fasting serum glucose, triglycerides, and LDL- and HDLcholesterol were measured using a Modular model P800 (Roche Diagnostics, GmbH, Mannheim, Germany). Hemoglobin $\mathrm{A}_{1 \mathrm{C}}$ was measured with a liquid chromatographic method (Variant II instrument, Bio-Rad Laboratories, Hercules, CA, USA). Three consecutive samples of first-void spot urine were analyzed for albumin and creatinine as described previously [23]. The median ACR was used in the analyses.

Creatinine was analyzed on the Hitachi Modular model using an enzymatic method (CREA Plus, Roche Diagnostics, GmbH, Mannheim, Germany). External quality assessment was provided by Labquality, Helsinki, Finland. The analysis at our laboratory was calibrated with serum X in the Nordic Reference Interval Project, which has been validated against isotope dilution mass spectroscopy [24]. The inter-assay coefficient of variation in the study period was $2.3 \%$.

Cystatin C was measured by particle-enhanced turbidimetric immunoassay using reagents from Gentian (Gentian, Moss, Norway) on a Modular E analyzer (Roche Diagnostics, GmbH, Mannheim, Germany). The inter-assay coefficient of variation in the study period was 3.1\%. 
External quality control was provided by Equalis (www.equalis.se). In 2013, 300 randomly selected samples frozen at $-80^{\circ} \mathrm{C}$ were reanalyzed with the same assay on a Cobas 8000 (Roche Diagnostics), and the baseline cystatin $C$ values were recalculated to values standardized to the international reference ERM-DA471/IFCC [25]. Details are given in the online Supplemental Material. eGFR based on creatinine (eGFR $\mathrm{crea}_{\text {cre }}$ ), on cystatin C (eGFR $\left.\mathrm{cys}_{\text {cys }}\right)$ and on both (eGFR $\left.\mathrm{R}_{\text {creacys }}\right)$ were calculated with equations developed by the CKD-EPI-Collaboration (Supplemental Table 1 in the online Supplemental Material) [5]. The performance of these equations in the RENIS-T6cohort with regard to bias, precision and accuracy has been reported previously $[12,26]$.

\section{Statistical Analyses}

Continuous variables are presented as the median (interquartile range). Differences across mGFR quartiles were tested with ANOVA or median, ordinal logistic, logistic or Poisson regression as appropriate. Tests for unadjusted linear and quadratic trends were performed using linear and squared terms for mGFR in the regressions. Serum triglyceride values were log transformed.

Adjusted models of the retinal variables were analyzed with multiple linear or logistic regression using mGFR, eGFR crea $\mathrm{eGFR}_{\text {cys }}$ or $\mathrm{eGFR}_{\text {creacys }}$ as the independent variable. Having a retinopathy grade greater than zero was analyzed as a dichotomous dependent variable in multiple logistic regression analyses. The central retinal artery and vein equivalents were analyzed in the same manner as the dependent continuous variables in multiple linear regression analyses. 
For each of the dependent variables above, separate multiple linear or logistic regression analyses were performed with mGFR, eGFR $\mathrm{crea}_{\text {, }}$ eGFR $\mathrm{Cys}_{\text {cr }}$ or $\mathrm{GFR}_{\text {creacys }}$ as independent variables, both divided into equation-specific quartiles and used as continuous variables. In model 1, we adjusted for age, gender, body weight, height, body mass index, antihypertensive medication, lipid-lowering and non-steroidal anti-inflammatory drugs; and in model 2 for the same variables as in model 1 and, in addition, history of first-degree relative with myocardial infarction before 60 years (yes/no), physical exercise (yes/no), daytime ambulatory MAP and PP, number of currently smoked cigarettes, LDL- and HDL-cholesterol, the log of fasting triglycerides and high-sensitivity C-reactive protein, urinary ACR and fasting glucose. Seemingly unrelated regression methods were used to test differences between the regression coefficients for the mGFR and the three eGFRs across the different regression models [27]. Body mass index was calculated as body weight divided by the square of height.

Due to logistic problems, retinal examinations were not performed in some patients. Retinal vessel or retinopathy data were missing in 7.9 and $8.4 \%$ of the subjects, respectively. In compliance with current recommendations, missing data were imputed using multiple chained imputation in STATA/MP 12.1 (StataCorp LP, Texas, USA, www.stata.com). All statistical tests were performed on 50 imputed datasets using mi estimate in STATA. The imputation model has been described in detail in a previous publication [28].

Statistical significance was defined as $\mathrm{P}<0.05$. 


\section{Results}

Of the 1627 subjects in the cohort, persons with micro- or macroalbuminuria $(n=44)$ or diabetes ( $n=33)$ were excluded. Three persons had both diabetes and microalbuminuria. Accordingly, 74 subjects were excluded, leaving 1553 for the present investigation (Figure 1).

There were differences across the mGFR quartiles with regard to several characteristics $(\mathrm{P}<0.05)$ (Table 1). These findings have been discussed previously [1,22,29].

In unadjusted analyses, there were no associations between the retinal changes and mGFR quartiles ( $\mathrm{P} \geq 0.05$ ) (Table 2). Quadratic trends were not statistically significant for any of the retinal variables in Table 2 .

In both model 1 (adjusted for age, sex, medication and anthropometric measures) and 2 (fully adjusted), an mGFR in the lowest quartile was associated with an increased odds ratio (OR) for retinopathy $(\mathrm{P}<0.05)($ Table 3). In model 2, the OR for retinopathy was 1.86 (95\%

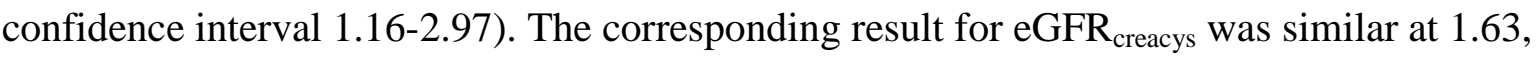
but not statistically significant. The ORs for eGFR crea $_{\text {and }}$ eGFR $\mathrm{cys}_{\text {cy }}$ were even lower (Table 3). The results when mGFR and eGFR were analyzed as continuous variables were similar (Table 3). There were no statistically significant quadratic trends across the quartiles for mGFR or any of the eGFR. In all possible pairwise comparisons between the linear trend ORs for mGFR and the three eGFRs, there were no statistically significant differences between the estimates in any of the models ( $\mathrm{P}>0.05)$. Seemingly unrelated regression methods were used for these tests. 
eGFR $_{\text {cys }}$ was associated with both the central retinal artery and vein equivalents in both model 1 and 2 in the multiple linear regression analyses (Table 4). Lower eGFR cys $_{\text {was }}$ associated with both wider retinal arteries and veins $(\mathrm{P}<0.05)$. eGFR $\mathrm{Cyscrea}_{\text {was }}$ associated with wider retinal veins in model $1(\mathrm{P}<0.05)$, but not in model 2. eGFR $\mathrm{crea}_{\text {in }}$ ine lowest quartile was associated with narrower veins in model $1(\mathrm{P}<0.05)$, but not in model 2 . There was no statistically significant quadratic trend across the quartiles for mGFR or any of the eGFR.

When comparing all possible pairs of linear trend regression coefficients for mGFR and the three eGFRs in both models in Table 4 with seemingly unrelated regression methods, all the differences between mGFR and GGFR $_{\text {cys }}$ were statistically significant. Likewise, all the differences between mGFR and $\mathrm{GFR}_{\text {cyscrea }}$ were statistically significant except for retinal arteries in the fully adjusted model. There was no statistically significant difference between

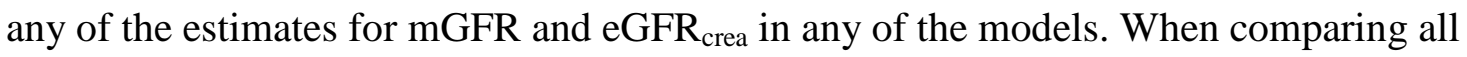
possible pairs of estimates for $\mathrm{eGFR}_{\text {crea, }}$ eGFR $\mathrm{Cys}_{\text {s }}$ and $\mathrm{GFFR}_{\text {creacys, }}$, the differences were all statistically significant (Table 4).

In a sensitivity analysis, all the analyses in tables 3 and 4 were repeated after exclusion of all subjects with mGFR, eGFR crea, $\mathrm{eGFR}_{\text {cys }}$ or $\mathrm{eGFR}_{\text {cyscrea }}$ lower than $60 \mathrm{~mL} / \mathrm{min} / 1.73 \mathrm{~m}^{2}$. In the multiple logistic regression analyses of retinopathy, the results were similar to the original analyses (Supplemental Table 2). In the multiple linear regression analyses of the retinal vessels, the associations between lower eGFR $_{\text {crea }}$ and both narrower arteries and veins were now statistically significant in both model 1 and 2 (Supplemental Table 3). The association between eGFR $\mathrm{cys}_{\text {s }}$ and wider arteries in the fully adjusted model 2 was no longer statistically significant. When comparing the estimates for mGFR and $\mathrm{eGFR}_{\text {crea, }}$, the differences were now all statistically significant except for the retinal arteries in model $2(\mathrm{P}=0.06)$. 


\section{Discussion}

We found an association between low mGFR and retinopathy in the general non-diabetic population, whereas there was no association between mGFR and retinal vessel diameters. If we had not measured GFR, but relied on one of the eGFR equations, the results would have been different. In particular, the use of $\mathrm{GFR}_{\mathrm{cys}}$ would have given the result that there was no association with retinopathy, but a strong association with wider retinal vessels for lower

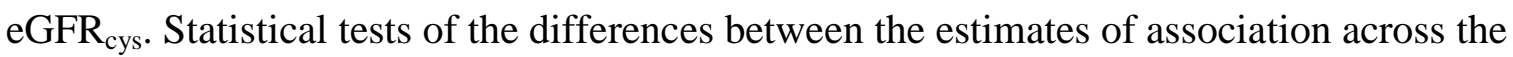
GFR assessments demonstrated that none of the eGFR was consistently similar to mGFR in their associations with retinal vessel diameters. eGFR crea $_{\text {was similar to }}$ GFR in the main analyses, but this result was not stable when persons with low mGFR or eGFR were excluded in a sensitivity analysis. eGFR $\mathrm{cys}_{\text {s }}$ performed worse than $\mathrm{eGFR}_{\text {crea }}$ or $\mathrm{eGFR}_{\text {creacys }}$ in both the main and the sensitivity analysis.

There have been several studies of non-GFR determinants of creatinine and cystatin C [1-4] which may explain the differences between mGFR and eGFR in the present study. However, we are not aware of any previous study where associations between pathological conditions and GFR estimates based on both markers have been compared with mGFR.

To our knowledge, there are no previous cross-sectional studies of the relationship between retinal changes and the GFR in healthy persons from the general population. There are divergent results of investigations of the association between renal vessel diameters and chronic kidney disease (CKD) defined as eGFR crea $<60 \mathrm{~mL} / \mathrm{min} / 1.73 \mathrm{~m}^{2}$. Whereas some studies have found an association between narrow retinal arteries or wider retinal veins and the odds of having CKD, others have not [30,31]. 
The results of longitudinal studies of retinal vessel diameters as risk factors for incident CKD also differ. The Multi-Ethnic Study of Atherosclerosis (MESA) found an association between narrower retinal artery caliber and CKD in Caucasians but not in other races [32]. However, this finding was not reproduced in the Beaver Dam CKD Study [33]. Both studies used eGFR $_{\text {crea }}$. The Beaver Dam CKD Study also tested a criterion for CKD based on the cystatin $\mathrm{C}$ level, which gave the same result as eGFR $\mathrm{crea}_{\text {. }}$ The present study indicates there is no association between retinal vessel diameters and mGFR in the general population. The estimates of the three eGFR equations were all different from each other, which may partly explain the divergent results of previous studies $(\mathrm{P}<0.05)$ (Table 4).

With regard to retinopathy, previous studies have found a positive relationship with CKD in non-diabetic persons $[30,31,34,35]$. Our results indicate that the cross-sectional association between reduced GFR and retinopathy extends into the normal GFR range and that it is independent of microalbuminuria (Table 3). This suggests that microvasculopathy may be the cause of the low mGFR of some of the subjects in the lowest quartile. Increasing age is associated with both retinal vascular damage and GFR decline, and mechanisms of aging could possibly be a common cause of both [8]. Although only mGFR was associated with retinopathy $(\mathrm{P}<0.05)$, none of the pairwise differences between mGFR and the three eGFRs were statistically significant when tested with seemingly unrelated regression methods.

Retinopathy has been found to be a strong independent predictor of stroke [7], but the risk for stroke associated with an eGFR $\mathrm{crea}_{\text {in }}$ ine low normal range has been found to be low and not statistically significant [36]. The attenuated odds ratios for retinopathy for $\mathrm{eGFR}_{\text {crea }}$ in the present study suggest that $\mathrm{GFR}_{\text {crea }}$ may underestimate the risk for stroke relative to mGFR. 
The attenuated odds ratios could be due to a low precision of eGFR or to the influence of nonGFR factors.

The different associations with retinal vessel diameters for $\mathrm{GFR}_{\text {crea }}$ and $\mathrm{eGFR}_{\text {cys }}$ were most likely due to the effects of non-GFR factors on cystatin C and creatinine. Although the differences were small, eGFR is typically used in large epidemiological studies where even small confounding effects may be significant. The difference of $8.1 \mu \mathrm{m}$ between eGFR $\mathrm{crea}_{\text {and }}$ eGFR $_{\text {cys }}$ for the estimate of the central retinal vein diameter in the lowest quartile (Table 4) in this study corresponds to a hazard ratio of 1.2 for intracerebral hemorrhage for $\mathrm{GFR}_{\mathrm{cys}}$

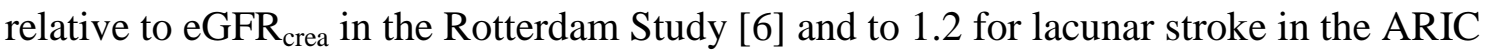
study [7].

The most important strength of our study was that it used mGFR measured as iohexol clearance in a large population survey. Because the RENIS-T6-cohort is homogenous with respect to age, ethnicity and comorbidity and because we excluded persons with CKD, CVD or diabetes, the effects of non-GFR factors may be less than in many other studies. This strengthens the conclusion that there are important differences between eGFR based on only one endogenous substance and mGFR. Both the creatinine and cystatin C assays were calibrated to international standards, and we were able to adjust our analyses for most important confounders, including fasting glucose and albuminuria.

One limitation of this investigation is that plasma iohexol clearance may slightly underestimate the gold-standard urinary inulin clearance [11]. To make GFR measurements in a large population survey possible, we chose to measure iohexol clearance with the singlesample method. Although some studies have found differences between single-sample and 
multiple-sample methods [37], other studies have found the methods similar [21,38-41]. It is unlikely that bias or imprecision of the GFR measurements relative to true GFR would be correlated with retinal changes. Accordingly, this would not be expected to influence our analyses, except possibly for an attenuation of estimates by regression dilution bias, which would not alter our conclusions. Another limitation of this investigation was that ethnicity was not investigated, as the RENIS-T6 included only persons of European ancestry. Also, because subjects with self-reported kidney disease were excluded, our results may not generalize to patients with chronic kidney disease.

We conclude that the association of retinal changes with mGFR and eGFR based on cystatin $\mathrm{C}$ and/or creatinine differs even when other risk factors are adjusted for. The use of eGFR in studies of the relationship between the eye and the kidneys will give biased results relative to mGFR and may fail to detect important relationships as well as identifying spurious ones. The magnitude of bias when eGFR is used as a predictor of other outcomes should be assessed in longitudinal studies comparing mGFR and eGFR. 


\section{Acknowledgements}

We thank Bjørg Skog Høgset, Saskia van Heusden and the staff at the Clinical Research Unit (University Hospital of North Norway) for assistance in planning the study, performing the procedures and collecting data according to the GCP standard. We also thank Harald Strand and the staff at the Department of Medical Biochemistry (University Hospital of North Norway) for performing the HPLC analyses of iohexol. We are grateful to all the participants in the RENIS-T6 cohort for making this study possible. Professor Ingrid Toft (deceased) of UiT The Arctic University of Norway contributed significantly to this project.

The Tromsø Study was supported by the University of Tromsø, the Research Council of Norway, the Northern Norway Regional Health Authority and Troms County Municipality.

\section{Disclosure Statement}

None of the authors have any conflicts of interest. 


\section{References}

1 Mathisen UD, Melsom T, Ingebretsen OC, Jenssen TG, Njølstad I, Solbu MD, Toft I, Eriksen BO: Estimated GFR is associated with cardiovascular risk factors independently of measured GFR. J Am Soc Nephrol 2011;22:927-937.

2 Rule AD, Bailey KR, Lieske JC, Peyser PA, Turner ST: Estimating the glomerular filtration rate from serum creatinine is better than from cystatin $\mathrm{C}$ for evaluating risk factors associated with chronic kidney disease. Kidney Int 2013;83:1169-1176.

3 Knight EL, Verhave JC, Spiegelman D, Hillege HL, de Zeeuw D, Curhan GC, de Jong PE: Factors influencing serum cystatin $\mathrm{C}$ levels other than renal function and the impact on renal function measurement. Kidney Int 2004;65:1416-1421.

4 Stevens LA, Schmid CH, Greene T, Li L, Beck GJ, Joffe MM, Froissart M, Kusek JW, Zhang Y, Coresh J, Levey AS: Factors other than glomerular filtration rate affect serum cystatin C levels. Kidney Int 2009;75:652-660.

5 Inker LA, Schmid CH, Tighiouart H, Eckfeldt JH, Feldman HI, Greene T, Kusek JW, Manzi J, Van LF, Zhang YL, Coresh J, Levey AS: Estimating glomerular filtration rate from serum creatinine and cystatin C. N Engl J Med 2012;367:20-29.

6 Wieberdink RG, Ikram MK, Koudstaal PJ, Hofman A, Vingerling JR, Breteler MMB: Retinal vascular calibers and the risk of intracerebral hemorrhage and cerebral infarction the Rotterdam study. Stroke 2010;41:2757-2761.

7 Yatsuya H, Folsom AR, Wong TY, Klein R, Klein BEK, Sharrett AR, for the ARIC Study Investigators: Retinal microvascular abnormalities and risk of lacunar stroke. Stroke 2010;41:1349-1355.

8 Wong CW, Wong TY, Cheng CY, Sabanayagam C: Kidney and eye diseases:

Common risk factors, etiological mechanisms, and pathways. Kidney Int 2014;85:1290-1302. 
9 Cruickshanks KJ, Ritter LL, Klein R, Moss SE: The association of microalbuminuria with diabetic retinopathy. The Wisconsin Epidemiologic Study of Diabetic Retinopathy. Ophthalmology 1993;100:862-867.

10 van Leiden HA, Dekker JM, Moll AC, Nijpels G, Heine RJ, Bouter LM, Stehouwer CD, Polak BC: Blood pressure, lipids, and obesity are associated with retinopathy: The Hoorn study. Diabetes Care 2002;25:1320-1325.

11 Stevens LA, Levey AS: Measured GFR as a confirmatory test for estimated GFR. J Am Soc Nephrol 2009;20:2305-2313.

12 Eriksen BO, Mathisen UD, Melsom T, Ingebretsen OC, Jenssen TG, Njølstad I, Solbu M, Toft I: Cystatin C is not a better estimator of GFR than plasma creatinine in the general population. Kidney Int 2010;78:1305-1311.

13 Eriksen BO, Melsom T, Mathisen UD, Jenssen TG, Solbu MD, Toft I: GFR normalized to total body water allows comparisons across genders and body sizes. J Am Soc Nephrol 2011;22:1517-1525.

14 K/DOQI clinical practice guidelines for chronic kidney disease work group: Part 4. Definition and classification of stages of chronic kidney disease. Am J Kidney Dis 2002;39:S46-S75.

15 American Diabetes Association: Diagnosis and classification of diabetes mellitus. Diabetes Care 2011;34:S62-S69.

16 Knudtson MD, Lee KE, Hubbard LD, Wong TY, Klein R, Klein BE: Revised formulas for summarizing retinal vessel diameters. Curr Eye Res 2003;27:143-149. 17 Wilkinson CP, Ferris FL, Klein RE, Lee PP, Agardh CD, Davis M, Dills D, Kampik A, Pararajasegaram R, Verdaguer JT: Proposed international clinical diabetic retinopathy and diabetic macular edema disease severity scales. Ophthalmology 2003;110:1677-1682. 
18 Bertelsen G, Erke MG, von HT, Mathiesen EB, Peto T, Sjolie AK, Njolstad I: The Tromso Eye Study: Study design, methodology and results on visual acuity and refractive errors. Acta Ophthalmol 2012

19 Rydstrom M, Tengstrom B, Cederquist I, Ahlmen J: Measurement of glomerular filtration rate by single-injection, single-sample techniques, using 51cr-edta or iohexol. Scand J Urol Nephrol 1995;29:135-139.

20 Brandstrom E, Grzegorczyk A, Jacobsson L, Friberg P, Lindahl A, Aurell M: GFR measurement with iohexol and 51cr-edta. A comparison of the two favoured GFR markers in Europe. Nephrol Dial Transplant 1998;13:1176-1182.

21 Eriksson CG, Kallner A: Glomerular filtration rate: A comparison between cr-edta clearance and a single sample technique with a non-ionic contrast agent. Clin Biochem 1991;24:261-264.

22 Mathisen UD, Melsom T, Ingebretsen OC, Jenssen TG, Njolstad I, Solbu MD, Toft I, Eriksen BO: Ambulatory blood pressure is associated with measured glomerular filtration rate in the general middle-aged population. J Hypertens 2012;30:497-504.

23 Solbu MD, Kronborg J, Eriksen BO, Jenssen TG, Toft I: Cardiovascular risk-factors predict progression of urinary albumin-excretion in a general, non-diabetic population: A gender-specific follow-up study. Atherosclerosis 2008;201:398-406.

24 Rustad P, Felding P, Franzson L, Kairisto V, Lahti A, Martensson A, Hyltoft PP, Simonsson P, Steensland H, Uldall A: The Nordic reference interval project 2000: Recommended reference intervals for 25 common biochemical properties. Scand J Clin Lab Invest 2004;64:271-284.

25 Grubb A, Blirup-Jensen S, Lindström V, Schmidt C, Althaus H, Zegers I: First certified reference material for cystatin C in human serum erm-da471/ifcc. Clin Chem Lab Med 2010;48:1619-1621. 
26 Melsom T, Fuskevag OM, Mathisen UD, Strand H, Schei J, Jenssen T, Solbu M, Eriksen BO: Estimated GFR is biased by non-traditional cardiovascular risk factors. Am J Nephrol 2015;41:7-15.

27 Zellner A: An efficient method of estimating seemingly unrelated regressions and tests for aggregation bias. J Am Stat Assoc 1962;57:348-368.

28 Eriksen BO, Lochen ML, Arntzen KA, Bertelsen G, Eilertsen BA, von Hanno T, Herder M, Jenssen TG, Mathisen UD, Melsom T, Njolstad I, Solbu MD, Toft I, Mathiesen EB: Subclinical cardiovascular disease is associated with a high glomerular filtration rate in the nondiabetic general population. Kidney Int 2014;86:146-153.

29 Melsom T, Mathisen UD, Ingebretsen OC, Jenssen TG, Njolstad I, Solbu MD, Toft I, Eriksen BO: Impaired fasting glucose is associated with renal hyperfiltration in the general population. Diabetes Care 2011;34:1546-1551.

30 Sabanayagam C, Shankar A, Koh D, Chia KS, Saw SM, Lim SC, Tai ES, Wong TY: Retinal microvascular caliber and chronic kidney disease in an asian population. Am J Epidemiol 2009;169:625-632.

31 Liew G, Mitchell P, Wong TY, Wang JJ: Retinal microvascular signs are associated with chronic kidney disease in persons with and without diabetes. Kidney Blood Press Res 2012;35:589-594.

32 Yau JW, Xie J, Kawasaki R, Kramer H, Shlipak M, Klein R, Klein B, Cotch MF, Wong TY: Retinal arteriolar narrowing and subsequent development of CKD stage 3: The Multi-ethnic Study of Atherosclerosis (MESA). Am J Kidney Dis 2011;58:39-46.

33 Sabanayagam C, Shankar A, Klein BEK, Lee KE, Muntner P, Nieto FJ, Tsai MY, Cruickshanks KJ, Schubert CR, Brazy PC, Coresh J, Klein R: Bidirectional association of retinal vessel diameters and estimated GFR decline: The Beaver Dam CKD Study. Am J Kidney Dis 2011;57:682-691. 
34 Wong TY, Coresh J, Klein R, Muntner P, Couper DJ, Sharrett AR, Klein BEK, Heiss

G, Hubbard LD, Duncan BB: Retinal microvascular abnormalities and renal dysfunction: The Atherosclerosis Risk in Communities Study. J Am Soc Nephrol 2004;15:2469-2476.

35 Edwards MS, Wilson DB, Craven TE, Stafford J, Fried LF, Wong TY, Klein R, Burke

GL, Hansen KJ: Associations between retinal microvascular abnormalities and declining renal function in the elderly population: The Cardiovascular Health Study. Am J Kidney Dis 2005;46:214-224.

36 Lee M, Saver JL, Chang K-H, Liao H-W, Chang S-C, Ovbiagele B: Low glomerular filtration rate and risk of stroke: Meta-analysis. BMJ 2010;341

37 Gaspari F, Guerini E, Perico N, Mosconi L, Ruggenenti P, Remuzzi G: Glomerular filtration rate determined from a single plasma sample after intravenous iohexol injection: Is it reliable? J Am Soc Nephrol 1996;7:2689-2693.

38 Sterner G, Frennby B, Hultberg B, Almen T: Iohexol clearance for GFR-determination in renal failure--single or multiple plasma sampling? Nephrol DialTransplant 1996;11:521525.

39 Lundqvist S, Hietala SO, Groth S, Sjodin JG: Evaluation of single sample clearance calculations in 902 patients. A comparison of multiple and single sample techniques. Acta Radiol 1997;38:68-72.

40 James TJ, Lewis AV, Tan GD, Altmann P, Taylor RP, Levy JC: Validity of simplified protocols to estimate glomerular filtration rate using iohexol clearance. Ann Clin Biochem 2007;44:369-376.

41 Bird NJ, Peters C, Michell AR, Peters AM: Comparison of GFR measurements assessed from single versus multiple samples. Am J Kidney Dis 2009;54:278-288. 


\section{Figure Legend}

Fig. 1 Study population derived from the Renal Iohexol-Clearance Survey in Tromsø 6 (RENIS-T6), which is an ancillary investigation of the sixth Tromsø Study. CKD indicates chronic kidney disease; GFR indicates glomerular filtration rate 
Table 1. Study population characteristics according to quartile of measured glomerular filtration rate. The RENIS-T6 Study.

Quartile of measured glomerular filtration rate, range $\left(\mathrm{mL} / \mathrm{min} / 1.73 \mathrm{~m}^{2}\right)$

Quartile $1(n=388) \quad$ Quartile $2(n=388) \quad$ Quartile $3(n=389) \quad$ Quartile $4(n=388)$

(21.9 to 82.8$) \quad$ (82.9 to 91.4$) \quad$ (101.4 to 100.9) $\quad$ (138.6)

P for linear trend

Characteristic

Measured glomerular filtration rate,

\begin{tabular}{|c|c|c|c|c|c|c|c|c|c|}
\hline $\mathrm{mL} / \mathrm{min} / 1.73 \mathrm{~m}^{2}$ & 76.5 & (70.5 to 80.0$)$ & 87.2 & (84.9 to 89.4$)$ & 95.9 & (93.7 to 98.3$)$ & 107.4 & (103.7 to 113.5$)$ & \\
\hline Female gender, $\%$ & 69.6 & & 55.2 & & 48.6 & & 31.7 & & $<0.001$ \\
\hline Age, years & 60.5 & (56.7 to 62.0 ) & 59.2 & (54.7 to 61.5$)$ & 57.8 & (54.2 to 61.0$)$ & 57.1 & (53.6 to 60.8$)$ & $<0.001$ \\
\hline Height, cm & 169.1 & (163.0 to 175.2$)$ & 169.7 & (164.4 to 177.0$)$ & 169.7 & (163.7 to 177.1$)$ & 173.0 & (166.4 to 178.3 ) & $<0.001$ \\
\hline Body weight, kg & 77.5 & (68.3 to 88.5$)$ & 77.6 & (68.2 to 87.6$)$ & 77.9 & (69.4 to 88.7$)$ & 81.3 & (71.1 to 90.7 ) & 0.04 \\
\hline Body mass index, $\mathrm{kg} / \mathrm{m}^{2}$ & 26.7 & (24.3 to 29.8$)$ & 26.6 & (24.2 to 29.3$)$ & 26.9 & $(24.6$ to 29.4$)$ & 27.0 & (24.7 to 29.8$)$ & 0.71 \\
\hline \multicolumn{10}{|l|}{ First-degree relative with myocardial } \\
\hline infarction before 60 years, $\%$ & 23.2 & & 16.0 & & 20.6 & & 19.6 & & $<0.001$ \\
\hline Current smoking, $\%$ & 18.3 & & 16.3 & & 19.3 & & 29.1 & & $<0.001$ \\
\hline $\begin{array}{r}\text { mean no. of cigarettes } \\
\text { smoked per day, if currently smoking }\end{array}$ & 10.4 & & 11.5 & & 12.1 & & 11.8 & & 0.05 \\
\hline Physical exercise ${ }^{\star}, \%$ & 50.5 & & 60.7 & & 59.5 & & 52.2 & & $0.99 \ddagger$ \\
\hline \multicolumn{10}{|l|}{ Blood pressure } \\
\hline \multicolumn{10}{|l|}{ Conventional } \\
\hline systolic, mmHg & 128.0 & (118.0 to 140.0 ) & 129.0 & (115.0 to 141.0$)$ & 127.0 & (116.0 to 140.0 ) & 127.0 & (118.0 to 138.0 ) & 0.83 \\
\hline diastolic, $\mathrm{mmHg}$ & 83.0 & (77.0 to 90.0$)$ & 83.0 & (76.5 to 90.0$)$ & 83.0 & (76.0 to 89.0$)$ & 83.0 & (77.0 to 89.0) & 0.85 \\
\hline \multicolumn{10}{|l|}{ Daytime ambulatory } \\
\hline systolic, mmHg & 128.0 & (119.8 to 137.3 ) & 128.5 & (118.8 to 136.6$)$ & 128.7 & (120.5 to 137.2$)$ & 132.1 & (123.5 to 139.9$)$ & $<0.001 \ddagger$ \\
\hline diastolic, $\mathrm{mmHg}$ & 80.2 & (74.2 to 86.3$)$ & 81.5 & (75.8 to 87.1$)$ & 81.8 & (76.3 to 86.8$)$ & 83.3 & (77.7 to 88.2$)$ & $<0.001$ \\
\hline mean arterial, $\mathrm{mmHg}$ & 97.3 & (90.5 to 103.6$)$ & 98.1 & (90.9 to 103.9$)$ & 98.1 & (91.6 to 103.9$)$ & 99.6 & (93.8 to 105.4$)$ & $<0.001$ \\
\hline pulse pressure, $\mathrm{mmHg}$ & 47.0 & (42.2 to 53.1$)$ & 46.4 & (41.7 to 51.6$)$ & 46.1 & (42.0 to 51.9$)$ & 48.2 & (43.2 to 53.0$)$ & $0.36 \neq$ \\
\hline Hypertension†, \% & 43.8 & & 42.8 & & 41.9 & & 37.9 & & 0.14 \\
\hline Antihypertensive medication, $\%$ & 21.1 & & 17.0 & & 16.7 & & 14.9 & & 0.02 \\
\hline Lipid-lowering medication, \% & 7.7 & & 5.9 & & 3.9 & & 7.2 & & 0.57 \\
\hline Non-steroidal antiinflammatory drugs, \% & 3.1 & & 2.3 & & 2.3 & & 1.8 & & 0.21 \\
\hline LDL-cholesterol, mmol/L & 3.60 & (3.00 to 4.20$)$ & 3.60 & (3.10 to 4.20$)$ & 3.70 & (3.20 to 4.30$)$ & 3.60 & (3.10 to 4.20$)$ & 0.92 \\
\hline HDL-cholesterol, mmol/L & 1.50 & (1.30 to 1.90$)$ & 1.55 & (1.30 to 1.80$)$ & 1.50 & (1.20 to 1.80$)$ & 1.40 & (1.20 to 1.70$)$ & $<0.001$ \\
\hline Triglycerides§, mmol/L & 1.10 & $(0.80$ to 1.50$)$ & 1.00 & $(0.70$ to 1.30$)$ & 1.00 & $(0.70$ to 1.50$)$ & 1.10 & $(0.70$ to 1.50$)$ & $0.40 \neq$ \\
\hline High-sensitivity C-reactive protein, mg/L & 1.30 & $(0.67$ to 2.36$)$ & 1.13 & (0.62 to 2.13$)$ & 1.17 & $(0.63$ to 2.18$)$ & 1.16 & (0.65 to 2.05$)$ & 0.37 \\
\hline Fasting serum glucose, $\mathrm{mmol} / \mathrm{L}$ & 5.20 & $(4.90$ to 5.50$)$ & 5.30 & (5.00 to 5.50$)$ & 5.30 & $(5.00$ to 5.60$)$ & 5.30 & (5.10 to 5.80$)$ & $<0.001$ \\
\hline Urine albumin-creatinine ratio, $\mathrm{mg} / \mathrm{mmol}$ & 0.22 & $(0.10$ to 0.53$)$ & 0.22 & (0.10 to 0.50$)$ & 0.17 & $(0.10$ to 0.46$)$ & 0.25 & (0.10 to 0.54$)$ & 0.15 \\
\hline
\end{tabular}

RENIS-T6 indicates the Renal lohexol-clearance Survey in Troms $\varnothing 6$.

Data are shown as median (interquartile range) or percent.

* Defined as leisuretime physical exercise leading to perspiration or breathlessness (yes/no).

$\dagger$ Defined as conventional systolic BP $>140$, conventional diastolic BP >90 or the use of antihypertensive medication.

$\ddagger \mathrm{P}<0.05$ for quadratic trend.

$\S$ Log-transformed when differences between quartiles were tested. 
Table 2. Retinal photography data according to the quartile of measured glomerular filtration rate. The RENIS-T6 Study.

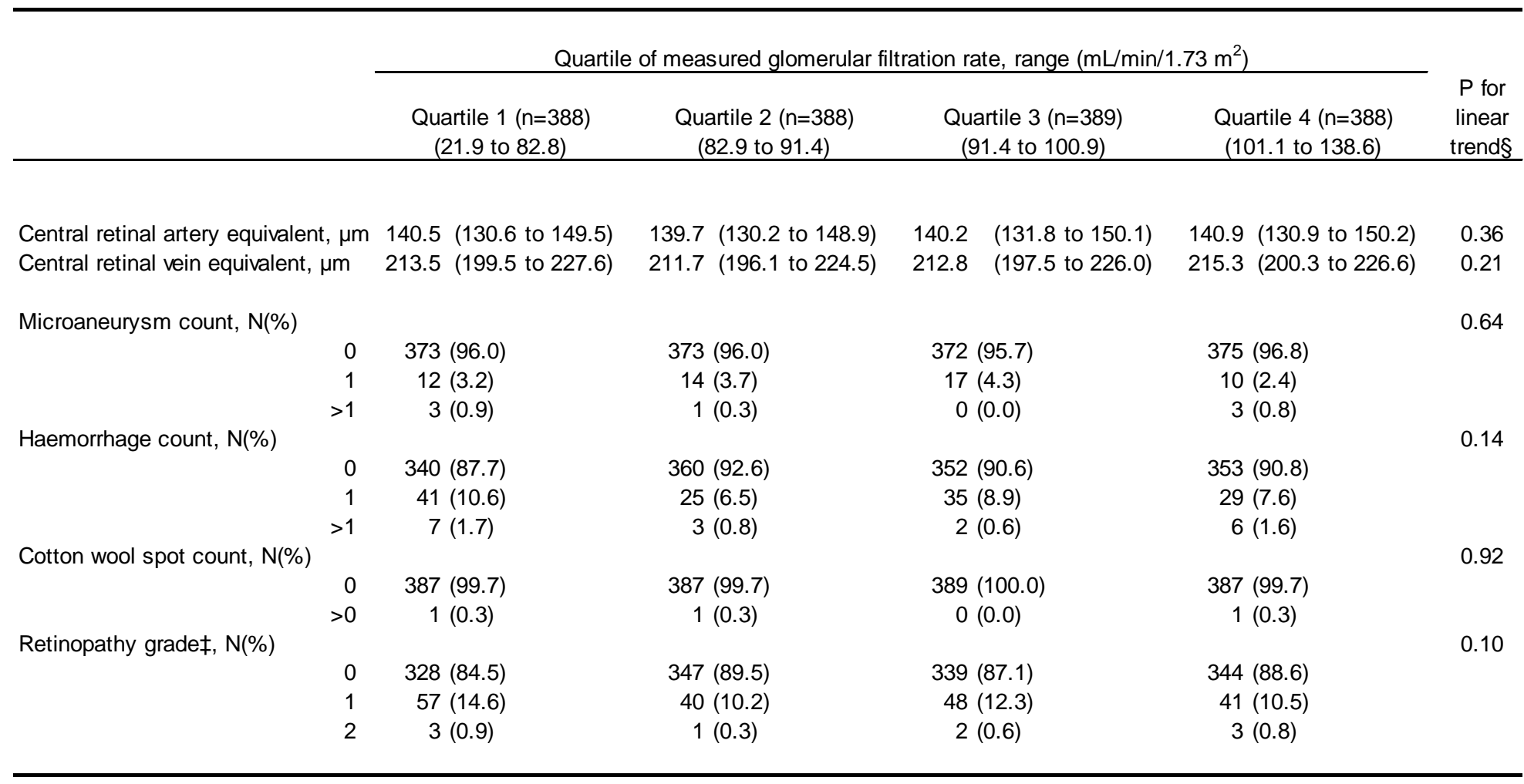

RENIS-T6 indicates the Renal lohexol-clearance Survey in Tromsø 6. Data are shown as the median (interquartile range) or percent. $\ddagger$ No subject had a retinopathy grade greater than 2 .

§Quadratic trends across the quartiles were tested for all variables, but none were statistically significant $(P \geq 0.05)$. 
Table 3. Multiple logistic regression analyses of associations between retinopathy and measured and estimated GFR. The RENIS-T6 Study.

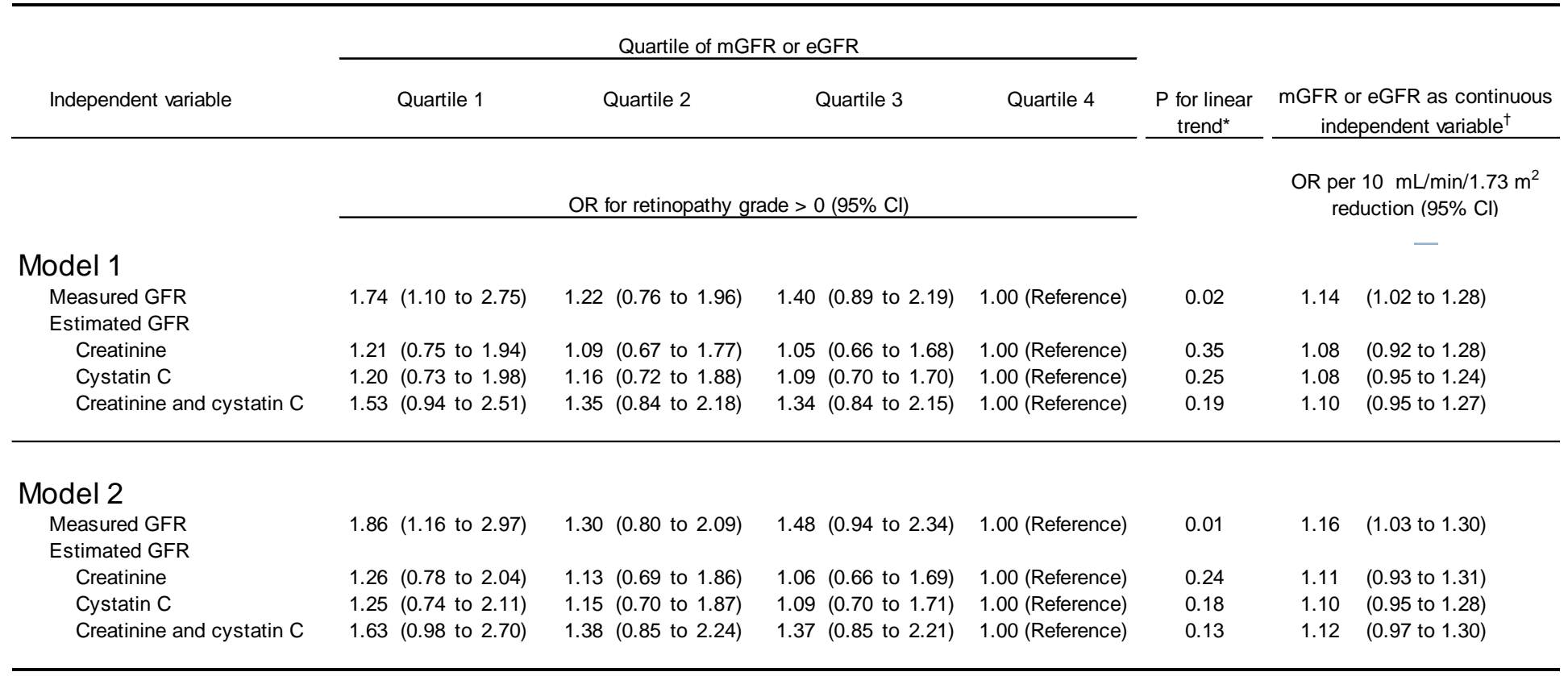

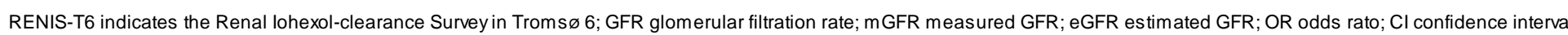
Model 1 was adjusted for age, sex, body weight, height, body mass index, antihypertenive medication, lipid-lowering drugs and non-steroidal antiinflammatory drugs. Model 2 was adjusted as model 1 and for first degree relative with myocardial infarction before 60 years of age, physical exercise, number of cigarettes currently smoked, ambulatory daytime mean arterial pressure, ambulatory daytime pulse pressure, LDL-cholesterol, HDL_cholesterol, fasting triglycerides and serum high sensitivity C-reactive protein, urinary

*In both models, quadratic trends across the quartiles were tested for all mGFR and eGFR, but none were statistically significant ( $P \geq 0.05$ ).

$\dagger$ In pairwise comparisons of the coefficients across the regression models with seemingly unrelated regression, none were statistically different ( $P \geq 0.05$ ). 
Table 4. Multiple linear regression analyses of associations between central retinal vessel equivalents and measured and estimated GFR. The RENIS-T6 Study.

Quartile of mGFR or eGFR

$\begin{array}{llcl}\text { Quartile 1 } & \text { Quartile 2 } & \text { Quartile 3 } & \text { Quartile 4 } \\ & & & \\ & & & \\ & & & \\ & & & \\ \text { Regression } & \text { Regression } & \text { Regression } & \text { Regression } \\ \text { coefficient } & \text { coefficient } & \text { coefficient } & \text { coefficient }\end{array}$

Model 1

Central retinal artery equivalent, $\mu \mathrm{m}$

Measured GFR
Estimated GFR
Creatinine

Cystatin C

Creatinine and cystatin C

Central retinal vein equivalent, $\mu \mathrm{m}$

Measured GFR

Estimated GFR

Creatinine

Cystatin C

Creatinine and cystatin C
(95\% Cl)

(95\% Cl)
$-0.85$

$(-2.56$ to 1.80$)$

$-2.03$

(-4.31 to 0.24$)$

$$
3.33
$$

(0.94 to 5.72 )

0.31

(-2.00 to 2.63$)$

$-0.65$

(-3.91 to 2.62$)$

$$
-3.85
$$

$(-7.25$ to -0.45$)$

7.69

(4.15 to 11.23 )

2.50

(-0.92 to 5.92$)$
(-2.98 to 1.29$)$

$$
-1.33
$$

(-3.65 to 1.00$)$

$$
2.14
$$

(-0.18 to 4.46$)$

$$
1.68
$$

(-0.55 to 3.90$)$

$$
-2.56
$$

(-5.73 to 0.61$)$

$-1.91$

(-5.36 to 1.54$)$

$$
4.45
$$

(0.95 to 7.94)

3.10

(-0.22 to 6.41$)$

$\begin{array}{cc}\mathrm{P} \text { for } & \text { mGFR or eGFR } \\ \text { linear } & \begin{array}{c}\text { as continuous } \\ \text { independent } \\ \text { trend }\end{array} \\ \text { variable }\end{array}$

Regression coefficient per 10
(95\% CI)

$(95 \% \mathrm{Cl})$

(95\%

trend

P-values for statistical test
of difference in linear
regression coefficients
between methods*

$\mathrm{mL} / \mathrm{min} / 1.73$

$\mathrm{m}^{2}$ reduction

$-0.27$

$(-0.83$ to 0.28$)$

$\begin{array}{cc}0.31 & 0.00 \\ (-1.83 \text { to } 2.44) & \text { (Reference) }\end{array}$

$\begin{array}{lll}0.29 & 0.00 \quad 0.08\end{array}$

$-0.74$

0.22

(-1.89 to 2.48) (Reference)

$1.36 \quad 0.00$

(-0.78 to 3.51) (Reference)

0.53

0.00

(-1.60 to 2.67) (Reference)

$-1.50$

0.00

(-4.67 to 1.67) (Reference)

0.19

$(-1.56$ to 0.09$)$

$0.01 \quad 0.92$

(0.23 to 1.60$)$

0.31

$(-0.40$ to 1.02$)$

mGFR eGFR crea eGFR $_{\text {cys }}$

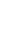




\section{Supplemental Material}

\section{Estimated and Measured GFR Associate Differently with Retinal}

\section{Vasculopathy in the General Population}

Bjørn Odvar Eriksen MD PhD ${ }^{1,4,7}$, Maja-Lisa Løchen MD PhD², Kjell Arne Arntzen $\mathrm{MD}^{3,5}$, Geir Bertelsen $\mathrm{MD}^{3,6}$, BrittAnn Winther Eilertsen $\mathrm{RN}^{7}$, Therese von Hanno $\mathrm{MD}^{3,9}$, Marit Herder $\mathrm{MD}^{2,8}$, Trond Geir Jenssen MD PhD ${ }^{1,10}$, Ulla Dorte Mathisen $\mathrm{MD} \mathrm{PhD}^{4}$, Toralf Melsom $\mathrm{MD} \mathrm{PhD}^{4}$, Inger Njølstad MD $\mathrm{PhD}^{2}$, Marit D. Solbu MD $\mathrm{PhD}^{4}$, Ellisiv B. Mathiesen $\mathrm{MD} \mathrm{PhD}^{3,5}$

\section{Nephron}




\section{Supplemental Methods}

\section{Calibration of the baseline cystatin C measurements}

In 2013,300 randomly selected baseline samples frozen at $-80^{\circ} \mathrm{C}$ were reanalyzed with the same cystatin C assay on a Cobas 8000 (Roche Diagnostics). The assay was calibrated with the Gentian calibrator (lot 1206401), which is fully traceable to the international reference ERM-DA471/IFCC [1]. Immediately before and after the series, an in-house control and an external control provided by Equalis were analyzed with identical results, which were identical to the established value for the inhouse control and 2.2\% lower than the consensus value of the external control. The $\mathrm{CV}$ for the assay at the time of reanalysis was $2.9 \%$. Using a Deming regression, the linear relationship between the two sets of measurements was found to be cystatin $C_{2013}=-0.064+$ cystatin $C_{2007} \times 0.998$. All the cystatin C results from 2007 were recalculated to standardized values using this equation. 


\section{Supplemental Reference}

1 Grubb A, Blirup-Jensen S, Lindström V, Schmidt C, Althaus H, Zegers I: First certified reference material for cystatin C in human serum ERM-DA471/IFCC. Clin Chem Lab Med 2010;48:1619-1621. 


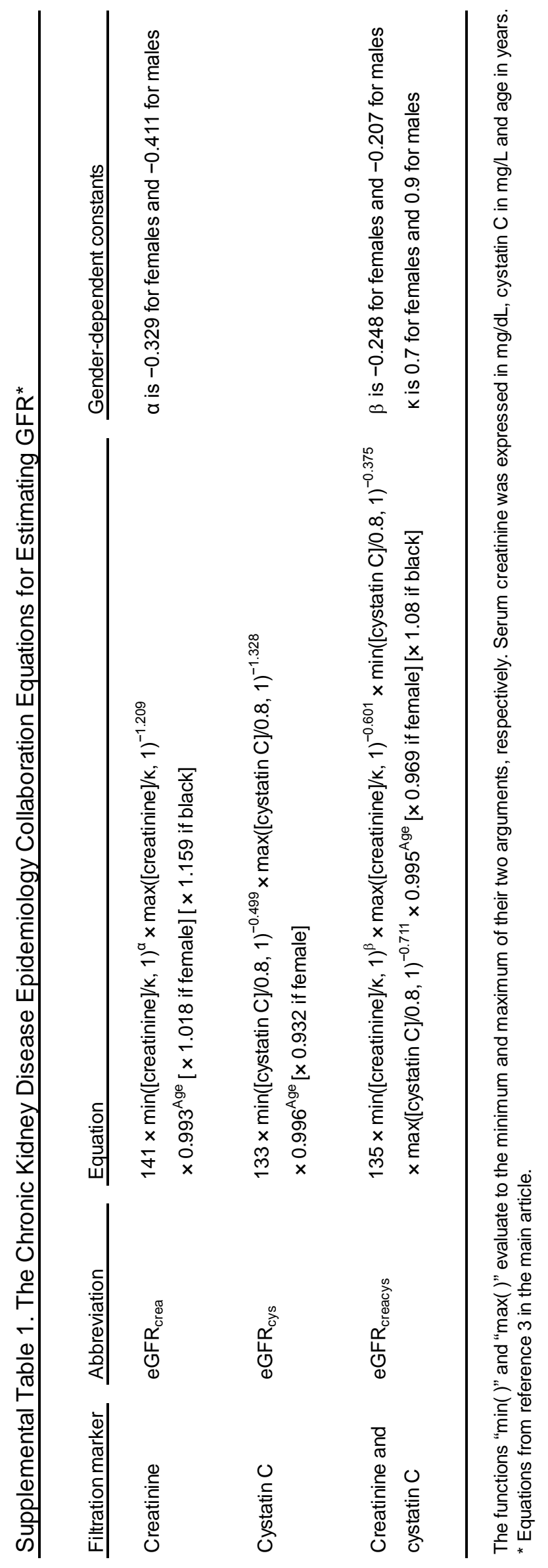




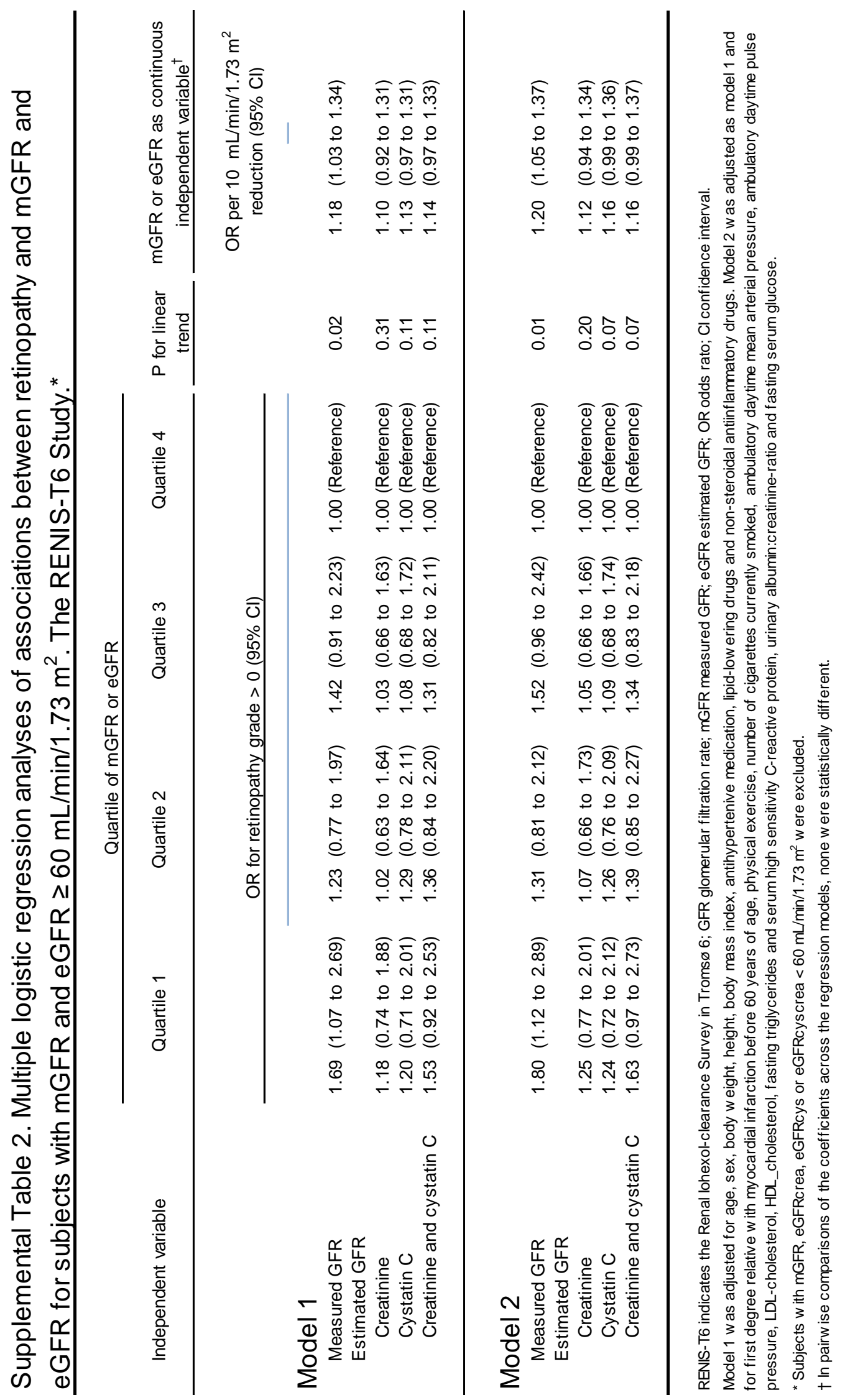


Supplemental Table 3. Multiple linear regression analyses of associations between central retinal vessel equivalents and mGFR and eGFR for subjects with $\mathrm{mGFR}$ and eGFR $\geq 60 \mathrm{~mL} / \mathrm{min} / 1.73 \mathrm{~m}^{2}$. The RENIS-T6 Study.*

\begin{tabular}{|c|c|c|c|c|c|c|}
\hline \multicolumn{4}{|c|}{ Quartile of mGFR or eGFR } & \multirow[b]{2}{*}{$\begin{array}{l}\text { P for } \\
\text { linear } \\
\text { trend }\end{array}$} & \multirow[b]{2}{*}{$\begin{array}{c}\text { mGFR or eGFR as } \\
\text { continuous } \\
\text { independent } \\
\text { variable }\end{array}$} & \multirow[b]{2}{*}{$\begin{array}{l}\text { P-values for statistical test of } \\
\text { difference in linear regression } \\
\text { coefficients between methods }\end{array}$} \\
\hline Quartile 1 & Quartile 2 & Quartile 3 & Quartile 4 & & & \\
\hline $\begin{array}{c}\text { Regression } \\
\text { coefficient }(95 \% \\
\text { Cl) }\end{array}$ & $\begin{array}{c}\text { Regression } \\
\text { coefficient } \\
(95 \% \mathrm{Cl})\end{array}$ & $\begin{array}{c}\text { Regression } \\
\text { coefficient } \\
(95 \% \mathrm{Cl})\end{array}$ & $\begin{array}{c}\text { Regression } \\
\text { coefficient } \\
(95 \% \mathrm{Cl})\end{array}$ & & $\begin{array}{c}\text { Regression } \\
\text { coefficient per } \\
10 \mathrm{~mL} / \mathrm{min} / 1.73 \\
\mathrm{~m}^{2} \text { reduction } \\
(95 \% \mathrm{Cl})\end{array}$ & eGFR $R_{\text {crea }}$ eGFR \\
\hline
\end{tabular}

\section{Model 1}

Central retinal artery equivalent, $\mu \mathrm{m}$ Measured GFR

$-0.90$

$(-3.10$ to 1.29$)$

Estimated GFR

Creatinine

Cystatin C

Creatinine and cystatin C

Central retinal vein equivalent, $\mu \mathrm{m}$ Measured GFR

Estimated GFR

Creatinine

Cystatin C

Creatinine and cystatin C

\section{$-2.45$}

(-4.73 to -0.16$)$

2.88

(0.51 to 5.25 )

0.16

(-2.15 to 2.48$)$

$-0.85$

(-4.15 to 2.44$)$

$-4.61$

(-8.00 to -1.22$)$

7.35

(3.80 to 10.89)

2.16

(-1.32 to 5.63$)$
$-0.67$

(-2.85 to 1.51)

$$
-1.24
$$

(-3.58 to 1.11)

2.04

(-0.26 to 4.34)

$$
1.58
$$

(-0.64 to 3.81$)$

$$
-2.44
$$

(-5.68 to 0.79$)$

$-1.77$

(-5.25 to 1.71$)$

3.90

(0.46 to 7.34 )

3.18

(-0.14 to 6.49$)$
0.19

(-1.96 to 2.34$)$

0.37

(-1.80 to 2.54$)$

1.36

(-0.77 to 3.50$)$

0.39

(-1.77 to 2.54$)$

$-1.18$

(-4.37 to 2.02$)$

$-0.38$

(-3.61 to 2.84$)$

5.21

(2.01 to 8.40$)$

1.40

(-1.84 to 4.64$)$
0.00

(Reference)

0.00

(Reference)

0.00

(Reference)

0.00

(Reference)

0.00

(Reference)

0.00

(Reference)

0.00

(Reference)

0.00

(Reference)
0.45

$-0.24$

$(-0.86$ to 0.38$)$

$0.01 \quad-1.15$

$(-2.03$ to -0.27$)$

$0.02 \quad 0.86$

(0.14 to 1.59$)$

$0.78 \quad 0.11$

$(-0.65$ to 0.86$)$

$0.37-0.42$

$(-1.35$ to 0.50$)$

$0.01 \quad-1.84$

(-3.15 to -0.53$)$

$<0.001 \quad 2.33$

(1.25 to 3.42$)$

0.86

$(-0.27$ to 1.99$)$

\section{Model 2}

Central retinal artery equivalent, $\mu \mathrm{m}$ Measured GFR

Estimated GFR

Creatinine

Cystatin C

Creatinine and cystatin C

-1.26
$(-3.38$ to 0.86$)$

$$
-2.23
$$

$(-4.43$ to -0.03$)$

2.33

(-0.03 to 4.69$)$

$-0.32$

$(-2.56$ to 1.92$)$

Central retinal vein equivalent, $\mu \mathrm{m}$ Measured GFR

Estimated GFR

$$
\text { Creatinine }
$$

Creatinine and cystatin C
(-4.38 to 2.28$)$

$-3.94$

(-7.33 to -0.55$)$

4.84

(1.20 to 8.48$)$

0.60

$(-2.87$ to 4.06$)$
$-1.05$
$-0.78$

(-2.88 to 1.32$)$

$$
-0.87
$$

(-3.10 to 1.37$)$

1.68

(-0.56 to 3.92$)$

1.46

(-0.67 to 3.59$)$

$-1.93$

(-5.21 to 1.36$)$

$$
-1.29
$$

(-4.73 to 2.16$)$

2.83

(-0.61 to 6.27$)$

2.94

(-0.32 to 6.20$)$
$-0.27$

(-2.34 to 1.79) (Reference)

$$
0.44
$$

(-1.62 to 2.50$)$

1.82

$(-0.24$ to 3.89$)$

$$
0.52
$$

(-1.54 to 2.58$)$

$-1.27$

(-4.44 to 1.91$) \quad$ (Reference)

$$
-0.07
$$

(-3.24 to 3.10$)$

$$
4.83
$$

(1.64 to 8.02$)$

$$
0.99
$$

$(-2.22$ to 4.19$)$

0.00
(Reference)
0.00

(Reference)

$$
0.00
$$

(Reference)

0.00
(Reference)

0.37

$0.00 \quad 0.02$

(Reference)

0.00

(Reference)

0.00

(Reference)

0.02
0.32

$-0.30$

$(-0.91$ to 0.30$)$

$0.02-1.05$

(-1.90 to -0.20$)$

$0.10 \quad 0.61$

$(-0.12$ to 1.33$)$

$-0.03$

(-0.76 to 0.70$)$

$-0.43$

(-1.37 to 0.51$)$

$-1.60$

(-2.92 to -0.29$)$

1.37

(0.24 to 2.51)

0.30

(-0.83 to 1.43$)$
0.02

$0.002<0.001$

$0.27<0.001<0.001$

0.02

$<0.001<0.001$

$0.01<0.001<0.001$

RENIS-T6 indicates the Renal lohexol-clearance Survey in Troms $\varnothing$ 6; GFR glomerular fittration rate; mGFR measured GFR; eGFR estimated GFR; Cl confidence interval; eGFRcrea, eGFRcys and eGFRcreacys GFR estimated from creatinine, cystatin $\mathrm{C}$ or both, respectively. Model 1 w as adjusted for age, sex, body w eight, height, body mass index, antihypertenive medication, lipid-low ering drugs and non-steroidal antiinflammatory drugs. Model 2 w as adjusted as model 1 and for first degree relative with myocardial infarction before 60 years of age, physical exercise, number of cigarettes currently smoked, ambulatory daytime mean arterial pressure, ambulatory daytime pulse pressure, LDL-cholesterol, HDL_cholesterol, fasting triglycerides and serum high sensitivity C-reactive protein, urinary albumin:creatinine-ratio and fasting serum glucose.

* Subjects with mGFR, eGFRcrea, eGFRcys or eGFRcyscrea $<60 \mathrm{~mL} / \mathrm{min} / 1.73 \mathrm{~m}^{2}$ w ere excluded.

$\dagger$ P-values for pairw ise comparisons of the linear regression coefficients across the regression models with seemingly unrelated regression. 